\title{
Inflation uncertainty and economic growth: evidence from the LAD ARCH model
}

\begin{abstract}
In this paper, we combined the panel data and least absolute deviation autoregressive conditional heteroscedastic $(\mathrm{ARCH})(\mathrm{L} 1-\mathrm{ARCH})$ model to infer on the relationship between inflation uncertainty and economic growth in five emerging market economies. Two interesting findings emerged from the analysis; first, we confirmed that the inflation uncertainty has a significant and negative effect on economic growth. Second, inflation is also an important variable and it is detrimental to economic prospects in the fast-growing Association of Southeast Asian Nations (ASEAN) economies. All in all, the empirical findings suggest that greater stability in the economy may be desirable in order to stimulate economic growth in the region.
\end{abstract}

Keyword: Inflation uncertainty; Economic growth; LAD ARCH 